\title{
THE 2016 AANS PRESIDENTIAL ADDRESS Leading the way
}

\author{
H. Hunt Batjer, MD, and Vin Shen Ban, MBBChir, MRCS, MSc \\ Department of Neurological Surgery, University of Texas Southwestern Medical Center, Dallas, Texas
}

\begin{abstract}
This AANS presidential address focuses on enduring values of the neurosurgical profession that transcend the current political climate. The address was delivered by Dr. Batjer during a US presidential election year, but the authors have intentionally avoided discussing the current chaos of the American health care system in the knowledge that many pressing issues will change depending on the outcome of the 2016 elections. Instead, they have chosen to focus on clarifying what neurosurgeons, and the American Association of Neurological Surgeons, in particular, stand for; identifying important challenges to these fundamental principles and values; and proposing specific actions to address these challenges. The authors cite "de-professionalism" and commoditization of medicine as foremost among the threats that confront medicine and surgery today and suggest concrete action that can be taken to reverse these trends as well as steps that can be taken to address other significant challenges. They emphasize the importance of embracing exceptionalism and never compromising the standards that have characterized the profession of neurosurgery since its inception. http://thejns.org/doi/abs/10.3171/2016.7.JNS161273
\end{abstract}

KEY WORDS neurosurgery; presidential address; AANS; leadership

$\mathrm{T}$ HE people in our specialty can change the world (Fig. 1). As neurosurgeons we stand as one in the fight for the public well-being, both at home and abroad.

- We stand for something

- We stand for excellence

- Excellence in the care of our patients

- Excellence in managing our professional responsibilities

- Excellence in how we treat our colleagues from other disciplines

- Excellence in how we treat each other

- Excellence in how we serve our communities

- Excellence in leading the way in American medicine

The American Association of Neurological Surgeons (AANS) stands for something also. We stand for a unified voice for neurosurgery in the United States and as a continental society of the World Federation of Neurosurgical Societies (WFNS) for all of North America. We have an increasingly complex organization with an increasingly broad portfolio of responsibilities. Leadership of our organization requires many people with very diverse areas of expertise and talent. In the course of this address, I will mention a few of those critically important people.

I will discuss the essence of what we are as neurosur- geons (Fig. 2). I have been blessed and honored with having represented neurosurgery in a variety of forums in and out of organized medicine. I have had the honor of testifying before Congress, testifying before the Institute of Medicine (IOM), the Accreditation Council for Graduate Medical Education (ACGME), the American Board of Medical Specialties (ABMS), the Association of American Medical Colleges, and numerous other forums. These years of service have given me a unique perspective of how our special discipline fits into the House of Medicine and how we are similar in some ways, but most importantly, how we are unique and very different.

From this perspective I will consider our legacy as innovators, our social contract, the challenges we face in honoring that social contract, our unique culture, and my thoughts about specific strategies that will strengthen medicine at large, with neurosurgery leading the way.

\section{What We Are Innovation}

Let us turn first to our legacy in innovation (Fig. 3). All neurosurgeons are innovators because we have to be. Our

ABBREVIATIONS AANS = American Association of Neurological Surgeons; $A B M S=$ American Board of Medical Specialties; ABNS = American Board of Neurological Surgery; $A C G M E=$ Accreditation Council for Graduate Medical Education; CTE = chronic traumatic encephalopathy; GME $=$ graduate medical education; IOM = Institute of Medicine; MOC = maintenance of certification; NFL = National Football League; PTSD = post-traumatic stress disorder; RRC = Residency Review Committee; VA = US Department of Veterans Affairs; WFNS = World Federation of Neurosurgical Societies; WHO = World Health Organization .

SUBMITTED June 1, 2016. ACCEPTED July 20, 2016.

INCLUDE WHEN CITING DOI: 10.3171/2016.7.JNS161273. 


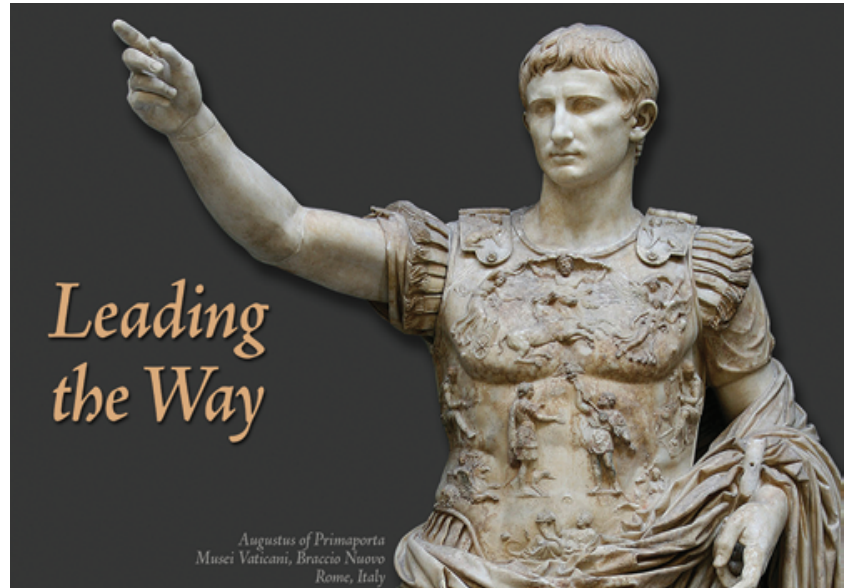

FIG. 1. "Leading the Way" title slide featuring the statue of Augustus of Primaporta (AD 14-AD 37) from the Musei Vaticani, Braccio Nuovo, Rome, Italy. Caesar Augustus led Rome's transformation from a republic to an empire, laying many of the foundations that exist today. Modified from a photograph by Till Niermann. GNU Free Documentation License version 1.2. Figure is available in color online only.

diseases are complex, our technical procedures are difficult and long, and the slightest error can result in catastrophe for our patients. We have to get out of trouble, often in situations that we have never seen before. Figure 4 shows the intraoperative rupture of a midbasilar trunk aneurysm which had bled 2 weeks prior to this surgical procedure. The innovation in this case was brought about by an astute neuroanesthesiologist, Dr. Tony Koht, who walked around behind me and quietly said, "Let me know if you want me to stop the heart." At that moment we had not ever before used adenosine for temporary circulatory arrest but in this case it was a godsend. ${ }^{9,10,13,39,41,72,85}$ This young patient and his surgeon are extraordinarily grateful to you, Tony.

We stand on the shoulders of giants in innovation. Take, for example, Dr. Egas Moniz. ${ }^{1,47}$ This physician trained in Portugal in the years before there was a formalized curriculum for neurosurgery. After graduation he went out and invented cerebral angiography. He later became interested in psychosurgery as he was developing severe gouty deformity of his hands. He had one of his young men travel elsewhere in Europe for formal training in neurosurgery and upon his return their work with prefrontal leucotomy resulted in a Nobel Prize in 1949.

Next I will turn to two unsung heroes, Drs. Rupert and Aidan Raney. These innovators developed numerous neurosurgical technologies, but perhaps most notable was capitalizing on the foundation that Cushing had laid with his pneumatic tourniquet to control scalp bleeding during craniotomy. Their elegant and simple Raney clips are now used worldwide. . $^{8,80}$

Dr. Louise Eisenhardt was another spectacular innovator. ${ }^{26}$ Her ideas generated the Cushing Brain Tumor Registry, which includes over 2200 specimens of human brain tumors perfectly cataloged and diagnosed, with pre- and postoperative photography and clinical vignettes. This neurosurgical treasure is now housed at Yale University. You may not know that Dr. Eisenhardt was one of the founding members of the Harvey Cushing Society, formed in 1931. The historic photograph in Fig. 5 was taken at the
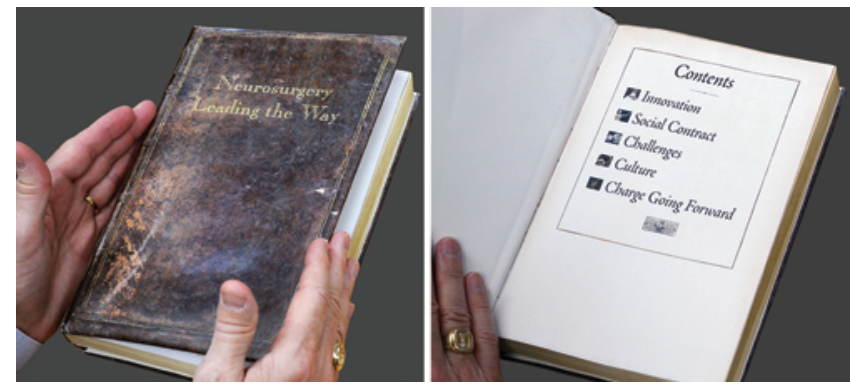

FIG. 2. This book illustrates neurosurgery's legacy in the House of Medicine and serves as a visual metaphor for reflection of the past and projection for the future. Photographer: Suzanne Truex. Reprinted with permission from the Department of Neurological Surgery, University of Texas Southwestern Medical Center. Figure is available in color online only.

first annual meeting of this society and shows Dr. Eisenhardt front and center. As you know, the Harvey Cushing Society later became the American Association of Neurological Surgeons. Dr. Eisenhardt served as the organization's first Secretary/Treasurer, the first Cushing Orator, the founding editor of the Journal of Neurosurgery (a position she held for over 20 years), and the society's first woman president.

Dr. Alim-Louis Benabid, our Richard Schneider lecturer, won the 2014 Lasker-DeBakey Medical Research award ${ }^{44} \mathrm{He}$ pioneered the critical new field of deep brain stimulation, allowing us to improve the lives of those suffering from movement disorders, not by creating lesions in their brain but by stimulating their brain. ${ }^{11,12,48,84}$ It is critical to note that 87 prior Lasker laureates have later received the Nobel Prize. Let us hope that number moves to 88 soon.

What about the next generation of surgeon-scientists? Dr. Edward Chang from the University of California, San Francisco, became the first neurosurgeon ever to win the Blavatnik National Award for Young Scientists in Life Sciences. ${ }^{19}$ His science involves the mechanisms by which human speech and language are processed. ${ }^{21,55,56}$

Neurosurgeons innovate in other ways as well. Consider our role in education-our neurosurgical boot camps have led the way, and other specialties are trying to figure out how to follow. ${ }^{34,63-66}$ Each of our incoming neurosurgical trainees acquires their basic skills in a totally risk-free environment. Many people have committed tireless hours to this task, but I will call out Drs. Nate Selden, Rich Byrne, Tom Origitano, Nick Barbaro, and Kim Burchiel for their leadership.

The AANS has followed the lead of Dr. Don Quest in investing in our future. Dr. Quest's policy of embracing talented medical students and leading them into the neurosciences has resulted in an extraordinary pipeline of people entering neurosurgery from Columbia University. Our AANS medical school chapters are now active in 51 medical schools around the country, and we now have over 1500 medical student members of the AANS.

Several years ago our Residency Review Committee was confronted with an innovative, yet disruptive idea. Put forward by the programs at the National Institutes of Health (NIH) and the University of Virginia, the concept was to leverage the high value of the NIH to create a new 


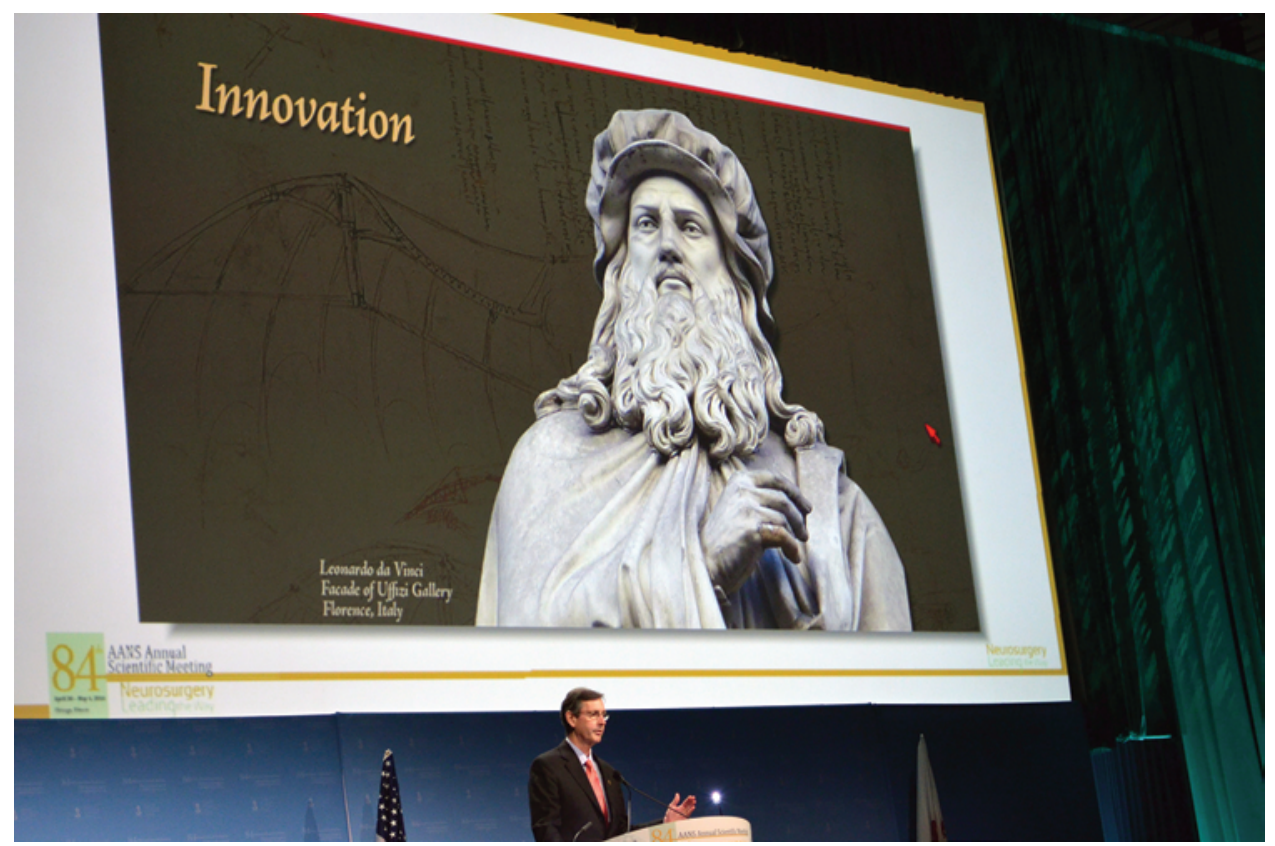

FIG. 3. Innovation slide from the 84th AANS Annual Scientific Meeting in Chicago, Illinois, May 2, 2016, featuring the statue of Leonardo da Vinci (16th century) from the facade of the Uffizi Gallery, Florence, Italy. Slide modified by Suzanne Truex from a photograph by Heather Harper-Troje. Reprinted with permission from the photographer. Photograph of Dr. Batjer speaking at the AANS Annual Meeting. Photographer: Scott Clamp. Reprinted with permission from the Department of Neurological Surgery, University of Texas Southwestern Medical Center. Figure is available in color online only.

pipeline of surgeon-scientists for the future. ${ }^{54}$ The concept was disruptive in that a number of ACGME standards could not be accomplished. Dr. Kim Burchiel and I went to the chief executive officer of ACGME, Dr. Tom Nasca, and he enabled the waiver of a number of standards and the creation of a new accreditation designation, Accreditation without Outcomes. By my last conversation with Dr. Burchiel, this program is on track and doing well. I thank Drs. Burchiel and Nasca for fostering innovation in neurosurgical training.

The Neurosurgical Summit represents a remarkable accomplishment, illustrating leadership by neurosurgery. Our membership societies, our board, our Residency Review Committee, and our Washington Committee come together under the aegis of the Society of Neurological Surgeons, an organization founded and based in research and education. In this way we can testify before Congress, the Centers for Medicare \& Medicaid Services (CMS), and all other regulatory bodies as an academy and not a
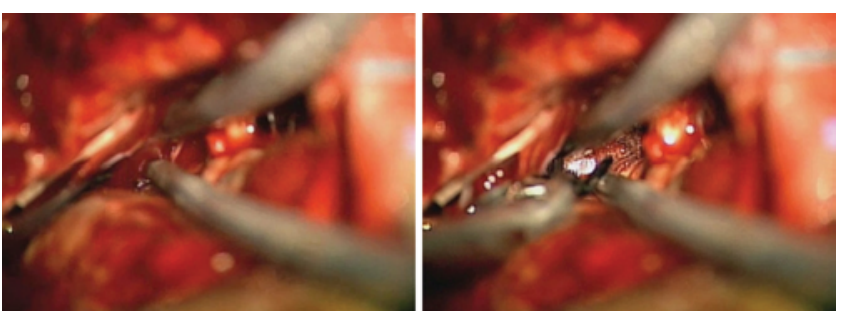

FIG. 4. Intraoperative rupture and control of a basilar trunk aneurysm. Left: Photograph showing blood obscuring the operative field and aneurysm. Right: Photograph obtained after administration of a bolus dose of adenosine, which caused temporary cardiac arrest and allowed the surgeon to apply the clip and secure the aneurysm. Figure is available in color online only. membership organization, which will be viewed as conflicted in these forums. This mechanism has allowed us to thread the needle between advocacy for neurosurgery and advocacy for the public interest. Fortunately for us, what is good for neurosurgery is also good for the public, and vice versa.

We have been challenged with recognition of subspecialization in neurosurgery. This problem was discussed in the late 1980s by Dr. Kemp Clark in his Elsberg lecture in New York which in that case dealt with pediatric neurosurgery (unpublished manuscript). We have held publically that the certificate shown in Fig. 6 represents proficiency across the spectrum of neuroscience. ${ }^{42}$ We all know that that is not quite accurate. The public has demanded transparency in terms of identification of experts in the various fields and recently we were confronted by two major threats: neurocritical care and endovascular neurosurgery. The United Council for Neurological Subspecialties (UCNS) with leap-frog recognition began certifying a host of new physicians in these two areas, some of whom were marginally trained. Our specialty came together under our Society of Neurological Surgeons Committee on Advanced Subspecialty Training (CAST) by joining hands in a unique way with the ACGME to strengthen our accreditation for enfolded and postgraduate fellowships. ${ }^{71}$ Our CAST committee joined hands with the American Board of Neurological Surgery (ABNS) to actually certify (when needed) physicians who had served the required training and been examined by our board. It should be noted that these relationships are unique in American medicine and have empowered neurosurgery to confront external threats. I want to thank Drs. Art Day, Bob Harbaugh, Steve Giannotta, Tom Nasca, Fred Meyer, and Jeff Bruce for their extraordinary leadership in this process. 


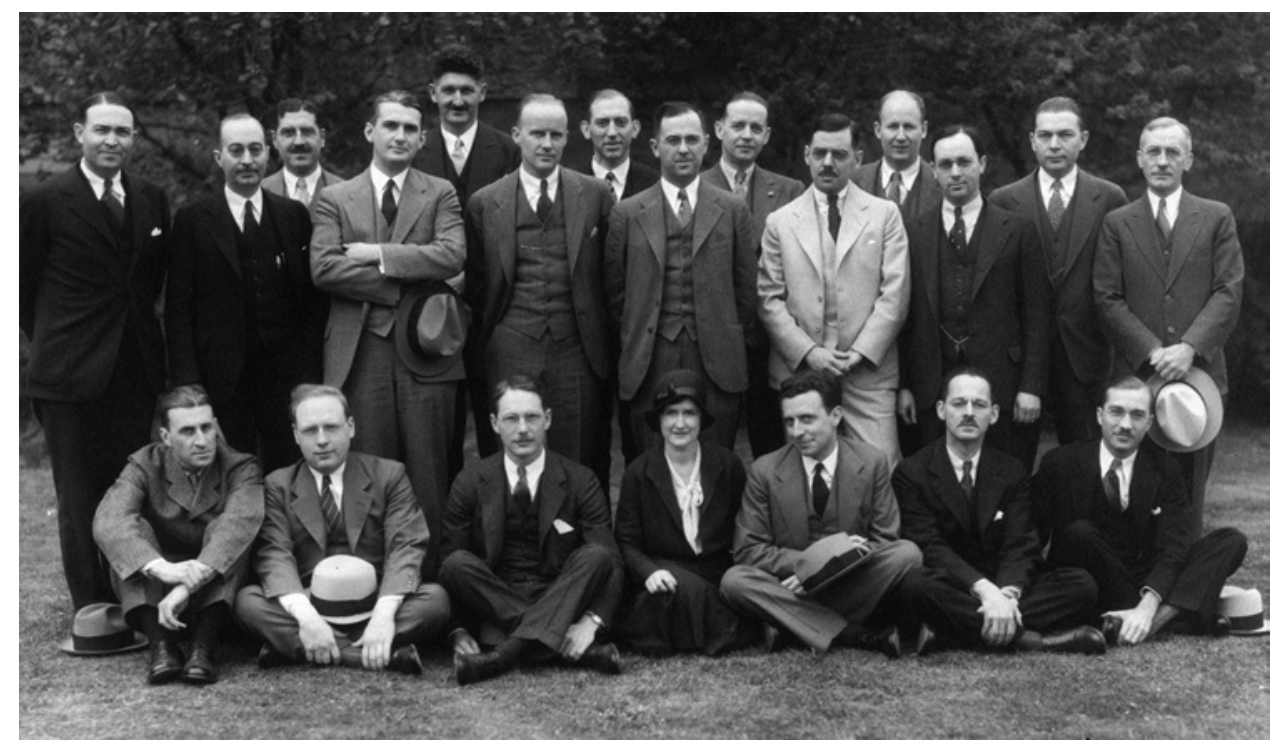

FIG. 5. First Annual Meeting of the Harvey Cushing Society, 1932. Dr. Louise Eisenhardt is seated in the center of the first row. Reproduced from the book History of the American Association of Neurological Surgeons 1931-1981, with permission from the AANS. Photographer: Richard Upjohn Light, MD.

\section{Our Social Contract}

A key differentiator which separates medicine from other sectors of our economy resides in our unique social contract. ${ }^{50}$ Under this contract our public has high expectations of us. They expect that we will be there when they need us and that we will serve them with the highest principles of ethics and beneficence. In turn, they honor us with great respect. Think for a moment about the current political debates and how the public and our media treat politicians. This never happens with physicians. Think back to the Social Security Amendments of 1965. This legislation was signed into law by President Lyndon Johnson and provided for Medicare coverage for our seniors. Interestingly, graduate medical education (GME) funding was embedded also in that legislation. Language included "the public good" and "enhanced level of care" as justification for that provision. Over the years much of this GME funding enabled us to care for indigent patients. While medicine at large holds the social contract, neurosurgery is in a very unique and privileged position in that contract because of the critical organ systems that we treat. Neurosurgeons are committed to the patient safety and quality movements. We foam in, and foam out. We support timeouts, checklists, debriefs, and root cause analyses. These activities make us safer at caring for our patients.

But neurosurgeons are also committed to getting better at what we do. Through our NeuroPoint Alliance and our Quality and Outcomes Database we are refining our ability to more precisely select patients who will benefit from our procedures. ${ }^{4}$ In the last few months the American Academy of Physical Medicine and Rehabilitation has joined hands with neurosurgery in a unique way. We now will have the dominant North American database for spine disease in which we can study patient-reported outcomes from medical interventions, physical modalities, percutaneous procedures, and open minimally invasive surgical procedures. We have already been joined by radiation on- cology to study outcomes from radiosurgical procedures.$^{68}$ A year ago I was sitting on an FDA panel when it became obvious that there were issues at FDA with pre- and postmarket surveillance for implantable neurological devices. Discussions have continued over the last several months and now appear to be in final phases to allow NeuroPoint

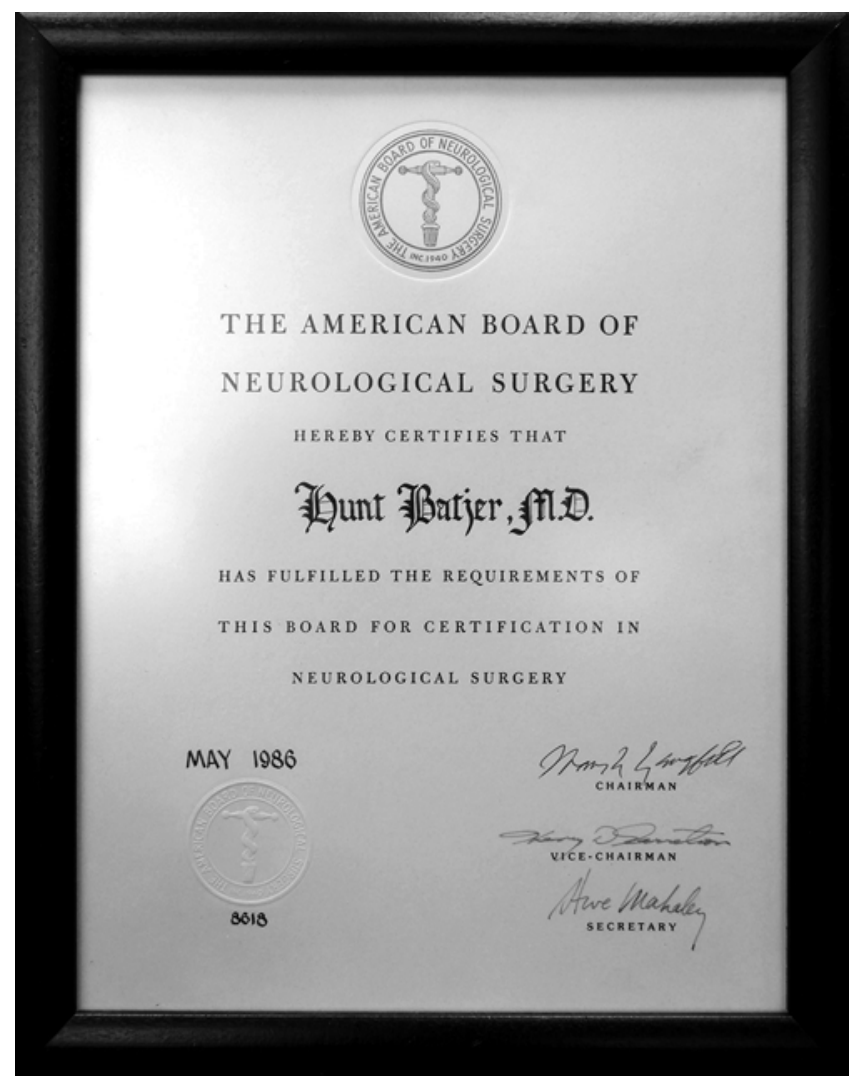

FIG. 6. American Board of Neurological Surgery certificate. 
Alliance to serve as a primary supporter of the FDA in these areas. I would call out Drs. Bob Harbaugh and Tony Asher for their extraordinary commitments to making the Quality and Outcomes Database a reality.

Finally, another element of our social contract concerns what I call the Court of Last Appeal. Patients come to us with horrible problems. Two conditions come to mind-severe spinal deformity and invasive cranial base neoplasms. Patients with these problems require highly invasive surgical procedures that are fraught with complications, prolonged length of stay, and high cost. If left untreated, however, these souls are doomed to early death and disability. We have to be there for them. Neurosurgeons, not insurers or hospital administrators, are uniquely trained to balance the risks of surgical intervention versus the natural history of disease.

Several years ago we were confronted with the perfect storm in the area of head trauma. A number of professional athletes, largely football players, were being diagnosed at autopsy as having chronic traumatic encephalopathy (CTE).$^{51}$ More conservative diagnostic principles led to an extraordinarily high number of youth athletes being diagnosed with concussive injuries..$^{53}$ The Centers for Disease Control and Prevention (CDC) revised their estimates to 3.8 million sports-related concussions in the United States per year. ${ }^{43}$ We were also shocked to learn of the number of female athletes, both girls and women, who were suffering concussions on the playing field. Much science needs to be done in this area, but there may be unique susceptibilities that women face..$^{53}$

Finally, our returning soldiers from the last two war theaters were found to include a distressingly high number suffering manifestation of head trauma and post-traumatic stress disorders (PTSD) ${ }^{75}$ The numbers are staggering and are in the hundreds of thousands. A number of us joined forces with professional sports, collegiate sports, and local school districts to try to get our arms around this problem. Several of us joined in nonpaid medical committee positions with the National Football League (NFL), and activities on that front resulted in the Lystedt Law being passed in all 50 states and the District of Columbia to protect youth athletes. ${ }^{32,33}$ The NFL has committed over \$100 million toward research both in the United States and overseas in the arena of sports-related head trauma. Having neurosurgery involved has dramatically impacted how we care for injured athletes. Rules that players with a suspected concussion are immediately removed from the game or practice have been extraordinarily beneficial. Moving the restraining line from the 30- to the 35-yard line has cut concussions on kickoff plays by $40 \% .{ }^{37}$ Return to play has been standardized across the NFL and the trickle-down has been immediate to collegiate and youth sports. Many of our members serve on the field in our NFL hub cities as unaffiliated neurotrauma consultants. I would like to thank each of you for your service. Having four additional expert eyes on the field to identify injured players and manage them correctly has been extraordinarily beneficial.

The public interest in this problem has resulted in enormous energy and resources being committed to making sports and military service safer. I call this flood of new ideas and companies Concussion.com. I believe we are on the threshold of having a new helmet device that will dramatically mitigate rotational forces. On the other hand, widely reported cases of former athletes being diagnosed with CTE have captured the sports and social media and created hysteria in this country. ${ }^{7}$ This hysteria has consequences. ${ }^{82}$ Eight months ago, a former National Hockey League (NHL) player who had been having some difficulties 15 or 20 years out from his playing career felt that he must have CTE. This appeared to be a reasonable assumption since the media was reporting "all players have it to some extent." Sadly, this former athlete took his own life to avoid having his family see him deteriorate from a chronic disease. His autopsy, done in Toronto, was negative for CTE. ${ }^{82}$ He needed care, not hysteria. This hysteria also feeds into the real epidemic of the 21st century, childhood obesity..$^{59}$ Parents are being intimidated to keep their kids home rather than encourage them to engage in healthy exercise and learn critical life lessons participating in competitive sports.

We need good science, not observational reporting largely from a single institution..$^{51}$ We need longitudinal studies to identify the incidence and prevalence of CTE and what the specific risk factors are. ${ }^{7}$ It seems astounding that the condition is so rare; why do not all former boxers have CTE?

Neurosurgeons must lead the way in the problem of brain injuries of all severities.

\section{Challenges}

\section{De-Professionalism and Commoditization of Medicine}

In my view, this is the most important threat that confronts medicine and surgery at this time. ${ }^{14}$ While each of us can list numerous examples, I was struck by a discussion that occurred at one of our surgical executive meetings earlier this year. We had a presentation by a pediatric surgeon at one of our children's hospitals reporting on a new platform to enhance operating room efficiency. After implementation of this technique, all the metrics changed from red to green and high-fives were generated. During questioning, however, the surgeon referred to "a little evil" that had to be confronted. This little evil is illustrated in Fig. 7. This little evil was the bond between a parent and a child. It had to be broken to facilitate wheels-in on time. I was stunned by that discussion and have since reflected on a concerning question: "Is that really what we are about?" If it reflects what we have become, we must reset our course immediately. Commoditization and de-professionalism degrade the stature and beneficence of medicine and surgery. If left unchecked they will allow us to be viewed as just another sector of the economy (with all the rights and privileges attendant to that new status).

\section{Duty Hours}

Those of us, including me, who trained in "prehistoric" times remember that being on one's feet for 130 or more hours a week is hard. The question is "does it harm patients?" There is a huge difference between a post-call physician going into a darkened room to read EKGs versus walking into a bright and bustling emergency department full of activity. Unfortunately, most of the sleep science that has led to current duty-hour standards occurred in the dark room environment. ${ }^{35,49}$ Several years ago Dr. 

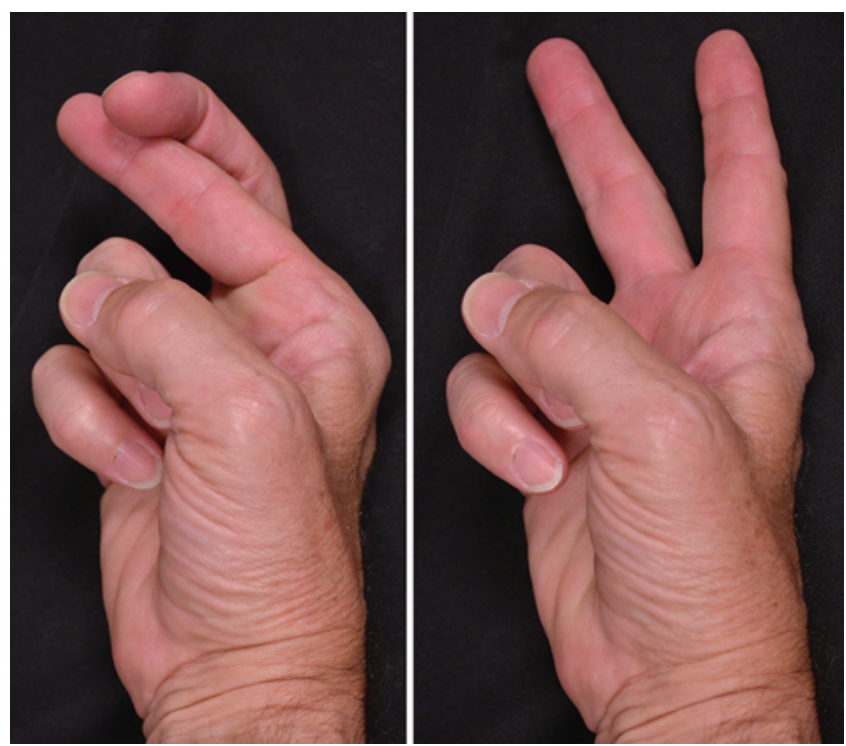

FIG. 7. De-professionalism is illustrated by the tightly coupled fingers representing the parent-child bond being pried apart to facilitate wheelsin to the operating room on time. Photographer: Suzanne Truex. Reprinted with permission from the Department of Neurological Surgery, University of Texas Southwestern Medical Center. Figure is available in color online only.

Aruna Ganju from Northwestern University clarified what we all have suspected-that neurosurgical trainees fatigue at a much slower rate than other specialties. ${ }^{36}$ This speaks to the unique genotype and phenotype that is attracted to and selected by the profession of neurosurgery. The death of Libby Zion in 1984 was tragic but completely unrelated to physician fatigue or long duty shifts. ${ }^{74}$ Nevertheless, this case worked its way through the New York court system culminating in a state law passed in 1989 restricting duty hours to 80 per week. ${ }^{57}$ Subsequent activities by the IOM and the ACGME led to standards enforced in 2003 that may have forever changed the way we train the next generation of physicians. ${ }^{61}$ Long duty shifts have been replaced by frequent hand-offs, breaks in continuity of care, and loss of professionalism. Our young neurosurgeons are put in an inconceivable double bind: either they honor their professional responsibilities and attend to a patient or family in need and then later lie about their duty hours, or worse, they walk away from their professional responsibilities and head to the elevator to keep their program in compliance. This entire scenario dishonors our specialty and our patients.

As the FIRST (Flexibility in Duty Hour Requirements for Surgical Trainees) trial has now reaffirmed, ${ }^{17}$ after 13 years of this experiment, there is no evidence whatsoever that restricting duty hours has had any positive impact on any measurable patient outcome. . $^{6,18,28,38,40,60,79,86}$

\section{The Institute of Medicine GME Report 2014}

This highly controversial report, if fully implemented, will be disastrous to academic medical centers and to specialty care..$^{15}$ Numerous elements of the report are gaining traction on Capitol Hill at this time. While the IOM committee recommended that funding be held whole at $\$ 15$ billion per year for the next 10 years, the specifics of the report clearly show that the available funding was reduced. Two new government bureaucracies would be created and presumably funded from GME resources, and a Transformational Fund that does not fund GME would be subtracted from this annual allocation as well. More concerning, however, is a new "per-resident rate" which is specifically designed to take trainees out of academic medical centers and place them in suburban or rural primary care settings - and the funding would follow the residents. As a result, our major academic medical centers would lose one-third of their current GME funding if this set of recommendations was adopted. As we know, much of that resource is directed toward enabling indigent care.

It is important to note that this is an extraordinarily primary care-centric report. It fails to acknowledge the looming shortage of surgeons, including neurosurgeons, that will be upon us by $2025.5,25$ In addition, it fails to acknowledge that the much-ballyhooed shortage of primary care doctors will be dramatically mitigated by midlevel providers practicing to the top of their licenses and by patient empowerment with new technologies that will enable people to monitor and manage their chronic illnesses at home.

\section{Electronic Health Records}

While many positive impacts on the way we care for patients have been achieved by electronic health records (EHRs), a number of perverse outcomes have occurred as well. ${ }^{24}$ I will first mention the demotion of physician/patient intimacy. Thirty-five percent of outpatient encounters are now spent with a physician facing a machine and not a patient. ${ }^{3}$ This is not neurosurgery. Neurosurgeons face their patients, touch their patients, bond with their patients, and comfort their patients. We are different from primary care. Copy and paste has taken us in a new direction as well. Our history of piles of unreadable handwritten etchings, with medical errors generated because pharmacists could not read our writing, has been replaced by miles and miles of redundant and meaningless data. For this particular chart, what exactly is the patient's diagnosis? What is the management plan? Why am I being consulted? A whole new category of medical errors has been created: "e-iatrogenesis." 24,81

\section{Fragmentation of Neurosurgery}

It is critical to remember that subspecialty certification places us on an extremely slippery slope. .2, $23,27,29,45,58,83 \mathrm{I}$ appeal to my colleagues, the directors of the ABNS, to remain very focused and to certify only in areas in which recognition is vital to the public interest and to the specialty. Too many other specialties have gone down this slippery slope and created havoc for their diplomates. In my view, only pediatric neurosurgery, neurocritical care, and endovascular neurosurgery meet the standard for subspecialty certification.

\section{Our Unique Culture}

What is the unique culture of neurosurgery? It is quite simple and can be summarized in two words: excellence and exceptionalism.

"Patients in need trump self and family every time."

"Neurosurgery is not for everyone." 
Think, for example, about the unique relationship we have with our patients. People come to see us at the worst possible moment of their life. They have been found to have a malignant brain tumor, or worse, their child has been discovered to have a malignant brain tumor. Coming to us during those moments honors us. We must return that honor with compassion, respect, empathy, and most of all, beneficence. Not long ago, a patient came to me on one of those days. She was a recently retired nurse who had developed a rapidly progressing neurological complex related to a largely thrombotic upper basilar giant aneurysm. After a full diagnostic workup, including a trial balloon occlusion test, she came to our university hospital one morning for a planned surgical Hunterian ligation of her upper basilar trunk..$^{70}$ When I saw her and her family in preoperative holding, they were extraordinarily upbeat. She stated "Good Morning, Doctor. Thanks so much for your help. Your team was extraordinarily kind to us, but I get it: I'm a dead person. If your plan saves me, I will be most grateful. If it doesn't, please don't let me linger."

When each of us encounters such a moment, it is important to reflect and internalize the incredible honor and respect we are given by our patients. They put everything on the line. We have to get it right every time. And it is important to keep in mind that sometimes good things happen to good people.

Our first two Washington leaders, Mr. Charles Plante and Ms. Katie Orrico, also represent our unique culture (Fig. 8). I got to meet Mr. Plante in the early 1980s when Dr. Kemp Clark was the president of the AANS. Mr. Plante had come to Dallas to meet with Dr. Clark, and for some reason I ended up sharing a lunch table with them at our faculty club. I was a brand new faculty member at that time. Their conversation is still etched in my mind. Mr. Plante interrupted Dr. Clark and said the following "Kemp, you're not getting it. When Congress calls upon me to render an opinion on a matter, they're going to get my very best researched opinion. Sometimes America's neurosurgeons are going to like that opinion and sometimes they won't." That comment represents extraordinary professional integrity. Mr. Plante mentored Katie Orrico and she has followed admirably in his most capable footsteps. Their professional integrity has allowed neurosur-

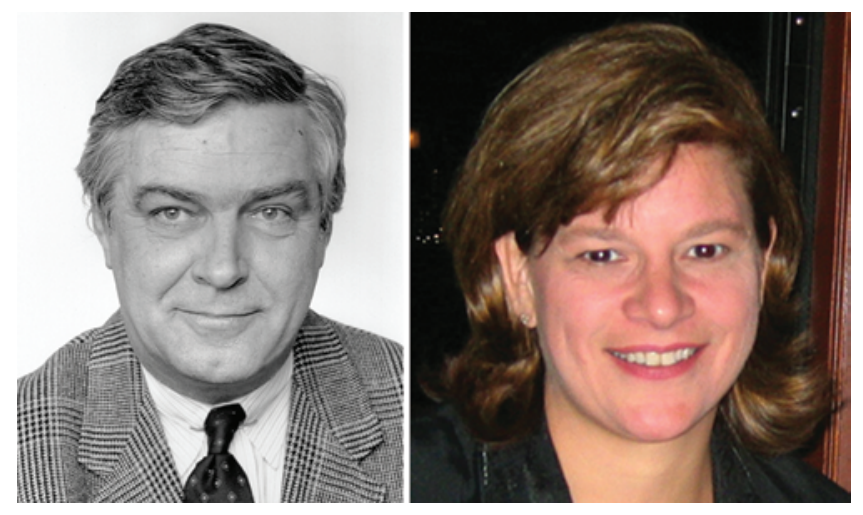

FIG. 8. AANS Washington office directors. Left: Charles Plante, JD. Courtesy of the Plante family with permission from the photographer, Frank Leary. Right: Katie O. Orrico, JD (current). Courtesy of Katie 0. Orrico. Figure is available in color online only. gery to be highly impactful in spite of our small size and represents the best of our exceptional culture.

\section{Charge Going Forward}

Is it possible that our initiatives taken now can influence the future? I believe that we are perfectly positioned to do just that. I would propose the following actions:

\section{Reverse the Trends of De-Professionalism and Commoditization}

This must be our Number One priority. How can we accomplish it?

First, we must always have higher standards in education, training, and practice. Dr. Tom Nasca once commented during a meeting of our Residency Review Committee (RRC) that he now understood why our standards were higher. He stated, "In your field your standards must be higher."

We must maintain our requirements for research. Other specialties are moving away from this commitment largely for financial reasons. It is critical that our trainees develop in an environment of scholarship and inquiry. They must ask questions and learn how to answer those questions. Not all neurosurgeons will be active in the research domain, but creating the proper culture in our training programs, our board requirements, and our RRC program requirements will ensure that all neurosurgeons understand the value of research. All neurosurgeons can contribute to our Quality and Outcomes Database (http://www.neuropoint. org/). This will enhance their practice. In addition, we can all invest in our patients' futures by committing resources to the Neurosurgical Research and Education Foundation (NREF, http://www.nref.org/) where dollars can be earmarked for specific donor intent. These principles will allow us to make progress in our worst diseases.

Maintenance of certification (MOC) has failed to achieve its lofty stated goals. In the 1990s, however, neurosurgery failed to lead. We felt that the new elements of MOC coming out of the American Board of Medical Specialties (ABMS) were, first of all, irrelevant to surgical practice (we were correct), we had concerns that the process would be very costly (we were correct), and we felt that that iteration of MOC would be of no benefit to surgical patients (we were correct). However, we were on the wrong side of history. The winds of change had already blown. Continuous certification was going to be a requirement for all physicians. Had we led the way at the ABMS, I believe there would have been a better outcome. One size fits all will always fail in medical policy. Why on earth should we have a high-stakes written examination rather than examine the way we practice? We consult each other and we consult the literature.

We are all aware of the debacle which occurred at the American Board of Internal Medicine (ABIM). ${ }^{31,62}$ This board developed many millions of dollars of new revenues through their MOC process out of the pockets of their diplomates. As you now know, they spent those monies very unwisely. ${ }^{30}$ These excesses occurred even as the failure rate on the ABIM cognitive examination increased to over $17 \%$. As a result our American Board of Neurological Surgery (ABNS) is now perfectly positioned to turn it up- 
side down. I encourage our board to not think outside the box-throw away the box! Forget the ABMS templates. Create what is right for our practitioners and our patients. Take that plan and join in the coalition of surgical boards and anesthesia. You will now have 11 of the 24 medical specialties with you, and that coalition will carry the day. Do what is right for neurosurgery and others will follow.

New cries for stricter duty-hour standards will definitely confront us in the future. They will come from either the groups represented in Fig. 9 or from other sources. ${ }^{20}$ My answer to that is quite simple. Fifty-six hours is the wrong answer for neurosurgery. ${ }^{6,18,28,40} \mathrm{I}$ am very pleased with the activities going on currently at the ACGME in which Dr. Kim Burchiel co-chairs an important task force. Organized neurosurgery via our Summit testified before the ACGME last month. I am very optimistic that as a result of these activities we will win back the PGY-1 year as a year of actual training and not a fifth year of medical school. I'm optimistic that we will win back our chief-resident year as a year of transition into independent practice where the emphasis is on the patient well-being and not the clock.

Neurosurgical training occurs in a complex milieu. Duty hours are simply one element and almost certainly an unimportant element in that environment. Let us return the focus to the patients' best interests and allow professionalism, not regulation, to manage fatigue in surgical practice. . $^{2,2,76}$

In these ways the forces of commoditization and deprofessionalism can be held at bay.

\section{Protect the Shield}

There are several disturbing cases active in the Ameri- can court system at this time. Several neurosurgeons have been charged with very serious offenses reflecting character flaws on their part. It is critical that individuals with such character flaws be identified early and prevented from ever putting the public at risk. This is a dramatic threat to our social contract. Whose responsibility is it? Is it the domain of the ABNS? The answer is no. Our board develops high educational standards and examines and certifies to those standards. I have personally seen a number of individuals with significant character flaws slip through those examinations unscathed. Is it the domain of our ACGME Residency Review Committee? No. A review committee ensures that the overall environment of learning is conducive to the transmission of the board-driven educational standards. The committee does not look at individual residents. The responsibility in my view resides in our training programs. Our faculties, program directors, and program chairs have 7 years of life with our new neurosurgeons. In almost every situation, they can identify individuals with substantial problems. It is our responsibility to step up to the plate and ensure that those individuals do not put the public at risk.

\section{Fix the VA Fiasco}

I do not know if the reports of over 300,000 deaths of our veterans awaiting care are accurate. ${ }^{46,67}$ My reason for saying that is that I do not believe that the VA (US Department of Veterans Affairs) has systems in databases that are competent to identify the correct number, and I am not confident that the VA has enough accountability that they would ever disclose the accurate number. I do know, however, that more than 2 years into the dramatic events
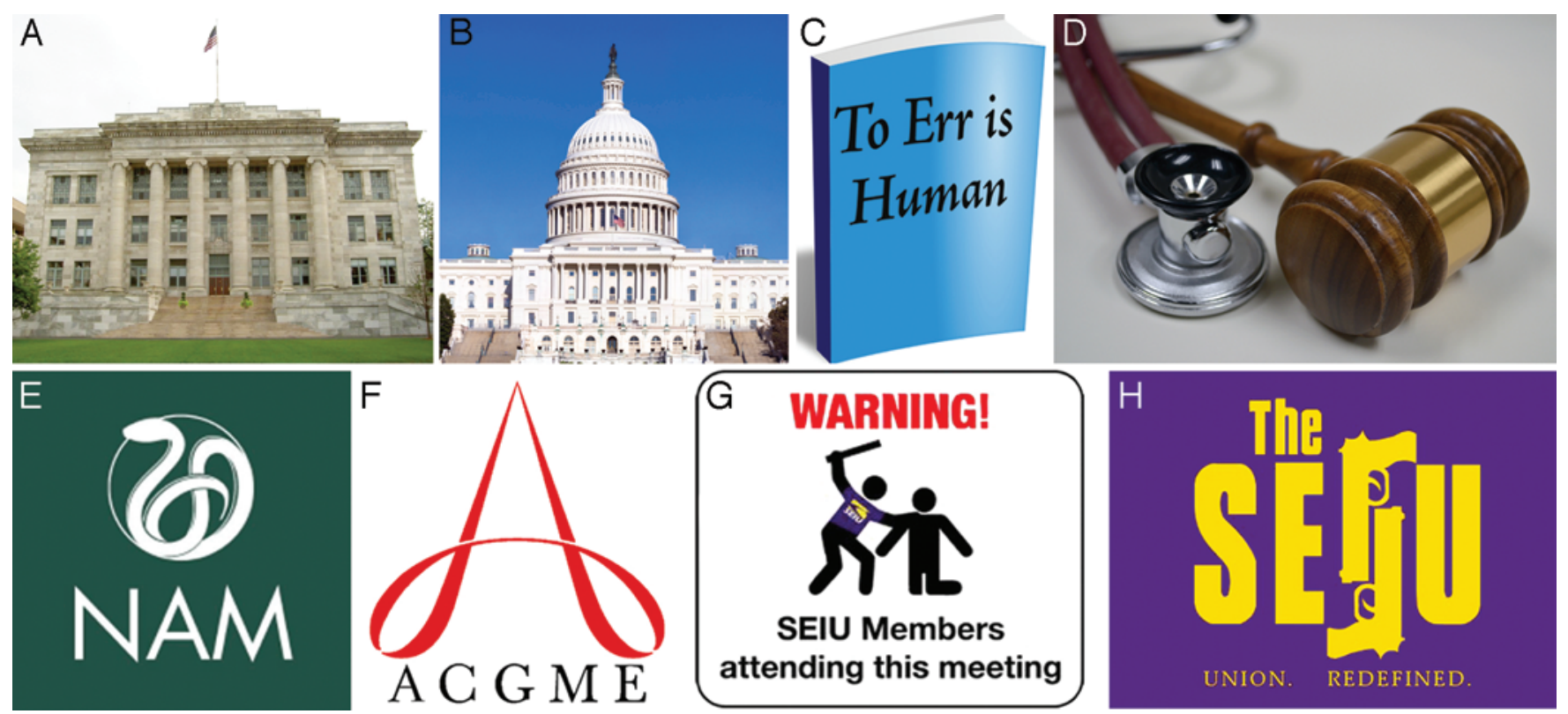

FIG. 9. Illustration of some of the participating groups involved in the duty hour/physician fatigue debate. The images represent Harvard University (A), Washington DC (B), To Err is Human report by the IOM (C), physicians and the legal system (D), the National Academy of Medicine (NAM) (E), the Accreditation Council for Graduate Medical Education (ACGME) (F), and the Service Employees International Union (SEIU) (G and H). Photograph of Harvard Medical School by Kentaro Matsui, public domain. Photograph of the US Capital by NoClip, pubic domain. Illustration of book To Err is Human and of stethoscope and gavel, Suzanne Truex. Reprinted with permission from Department of Neurological Surgery, University of Texas Southwestern Medical Center. Figure is available in color online only. 
reported from the VA in Arizona, we still have 480,000 veterans waiting more than 30 days to receive care. ${ }^{69}$ This is appalling, considering that over the same interval administrative positions at the VA have increased by $160 \%$, $\$ 142$ million in new bonuses have been distributed, and the VA health budget has mushroomed to $\$ 60$ billion annually. ${ }^{77,78}$ You would think that we would be able to provide "reasonable" care to the 7 million veterans receiving care each year at our VAs. It is my belief that the overhaul strategies being discussed in Congress and even in the presidential debates represent a fool's errand. I believe that the VA is fundamentally flawed. I would hope rather that we could influence legislation to progressively defund the VA over time. I would hope that we could transfer those savings into charge cards such that those who have served our country could receive Medicare-level coverage at any care site that they choose. Congressman Phil Roe from Tennessee, who is a physician, is completely onboard with this principle. He is planning pilot studies using these charge cards at various VA systems around the country. We will obviously participate with him, and I encourage each of us in various areas of the country to join him in this study as well. Perhaps over time the VA could be reduced to outpatient facilities focusing on unique veterans' challenges such as PTSD and prosthetics.

\section{International Outreach}

I referred earlier to our role as a continental society of the World Federation of Neurosurgical Societies (WFNS). Over the past 2 years I have witnessed firsthand and participated in events in which the strength of our AANS brand was dramatically obvious. We created change on the international stage. At our Board of Directors meeting during the 2016 Annual Meeting, at our table we hosted as liaison the president and president-elect of the WFNS as well as each continental society president. In addition, our own Dr. Walt Johnson is now uniquely positioned at the World Health Organization (WHO) to make a dramatic

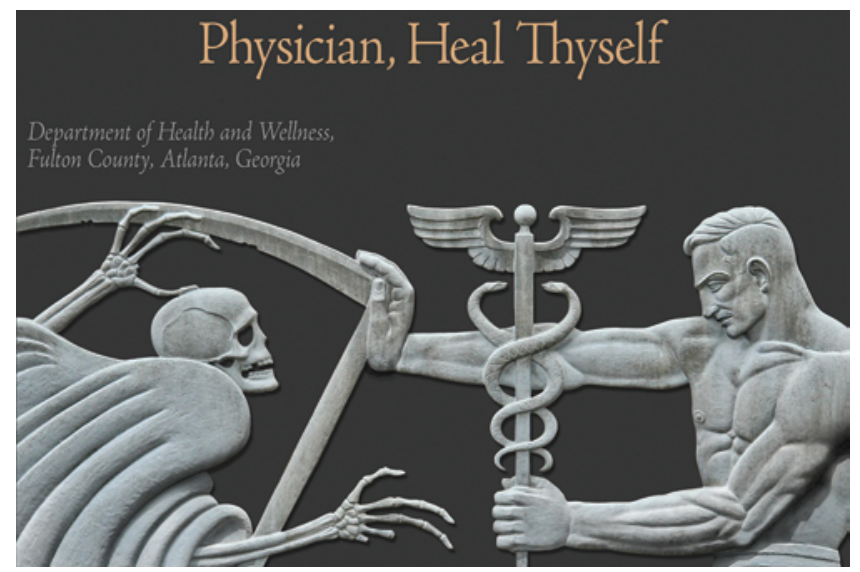

FIG. 10. "Physician, heal thyself" slide featuring frieze from the Department of Health and Wellness, Fulton County, Atlanta, Georgia. You are in the "hot seat" as a neurosurgeon-take care of yourself. Photograph used with permission from the photographer, Wendy Darling, Woodruff Health Sciences Center Communications, Emory University. Figure is available in color online only. impact. The WHO has redefined surgery as an element of primary health care with the potential to dramatically improve care in lower- and middle-income countries. . $^{1673}$

Think for a moment about the possibility of the AANS and other North American entities, including the Foundation for International Education in Neurological Surgery (FIENS), joining hands with the WHO. Think for a moment about a common problem such as traumatic brain injury or hydrocephalus and a disruptive new idea. If we were to come up with such an idea and reach out to the Bill and Melinda Gates Foundation, for example, or Ann Lurie in Chicago, we could dramatically reduce suffering across the world.

\section{Physician, Heal Thyself}

We cannot take care of our patients if we are not well (Fig. 10). Neurosurgery is a difficult life. It has been described as "the hot seat." Three recent deaths of young neurosurgeons in their prime of life have hit me very personally. I will always remember Drs. Getch, Parsa, and Kuntz. I can assure you that the AANS leadership is focused on making us better patients. Please get blood tests, colonoscopies, and mammograms. Life is a marathon, not a 100-yard dash: go the distance.

Through these straightforward and accomplishable strategies, the singular culture of neurosurgery and the deep values of our social contract will favorably impact medicine and our position in society (Fig. 11).

We must embrace our exceptionalism and never compromise our standards.

\section{Closing Remarks}

In closing, I am reminded of the words of my father: "Son, in this great country of ours you can accomplish anything that you are willing to work hard enough for." Each of you in this theater has realized Dad's American Dream.

- The people in this specialty can change the world.

- Thank you for your devotion to learning.

- Thank you for caring for the sick.

- Thank you for your commitment to advancing health care through research.

- Thank you for your commitment to improving suffering around the world.

- Thank you for your commitment to the values embedded in our Hippocratic Oath.
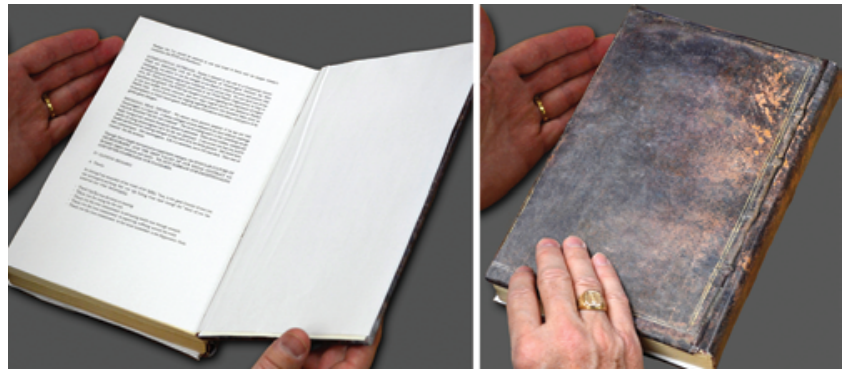

FIG. 11. The neurosurgery culture and the values of our social contract embolden us to develop succinct strategies to ensure our profession is protected and uncompromised. Figure is available in color online only. 
Regardless of what the future holds we will prevail.

- We have control over our destiny!

- We stand as one!

-We stand for something!

-We stand for excellence!

- We will lead the way!

- Godspeed and God bless our most noble profession.

\section{Acknowledgments}

I want to call out first our extraordinary Executive Committee for the past year. These leaders have been exemplary in representing you and our committee has functioned purely by consensus at all times. The same can be said for our full Board of Directors. I want to thank our excellent senior management team. Tom Marshall served as our Executive Director for 15 years, culturally and financially transforming the organization. Last November, Kathleen Craig took over the reins as Executive Director and has already distinguished herself in this new capacity. Our best years are ahead. I want to thank our 2016 Annual Meeting planners. Dr. Aviva Abosch did an extraordinary job with our scientific program while Dr. Reg Haid managed every other aspect of the Annual Meeting. He was available to keep me out of trouble 24/7/365. It was terrific working with Dr. Rich Byrne on our local arrangements as well as our Chicago "Leading the Way" videos covering Chicago sports, Chicago architecture, and Chicago neurosurgery. I want to thank Dr. Jon Robertson for his extraordinary leadership of our Neurosurgery Research and Education Foundation (NREF). He has transformed this component of our organization, enabling our members to contribute to our future in very unique ways, particularly the Honor Your Mentor funds. Our Washington activities represent a core responsibility of the AANS. Dr. John Wilson completed his term as chair of our Washington Committee in December, having done an exemplary job, and Dr. Shelly Timmons took over as our new chair in January. Neurosurgery is in very capable hands. I want to thank the real Dream Team that we have assembled at UT Southwestern Medical Center in Dallas. These extraordinary people are a real pleasure to work with on a day-to-day basis. Thanks to all of you for your support during these last few challenging years. I want to thank my CNS (Congress of Neurological Surgeons) counterparts, Drs. Nate Selden and Russ Lonser. This year caps decades of collaboration with both of these fine men. I want to thank my colleagues from Aequanimitas. This set of relationships has been much more than a travel club. Our children have grown up together. The ideas that have come out of those casual discussions over the years have been transformative to each of us. I want to thank my clinical mentors. First, AANS Past President Dr. Kemp Clark. Second, master surgeon Dr. Duke Samson. Third, master surgeon and AANS Past President Dr. Charles Drake. I thank each of you from the bottom of my heart for having made me a neurosurgeon. In addition to those outstanding leaders, I have been mentored by many other people, only a few mentioned here-Drs. Donald Quest, Ralph Dacey, Dan Barrow, Art Day, Steve Giannotta, Roberto Heros, Rich Ellenbogen, Tom Nasca, Phil Stieg, Bernard Bendok, Kim Burchiel, Bob Harbaugh, Mark Hadley, Nelson Oyesiku, Mitch Berger, and Commissioner Roger Goodell. You would think that with all the mentorship I have received that I would know a bit more! I want to call out three extraordinary people from our team in Dallas-Mr. Scott Clamp, Ms. Suzanne Truex, and Dr. Vin Shen Ban. Our annual meeting was flavored with the talents and energies of these three extraordinary people. Finally, I want to express my deepest thanks and affection for my family, Team Batjer. These lovelies have been incredibly supportive over all the challenging years.

\section{References}

1. American Medical Association: Antonio Egas Moniz (18741955), Portuguese neurologist. JAMA 206:368-369, 1968
2. Arora V, Dunphy C, Chang VY, Ahmad F, Humphrey HJ, Meltzer D: The effects of on-duty napping on intern sleep time and fatigue. Ann Intern Med 144:792-798, 2006

3. Asan O, D Smith P, Montague E: More screen time, less face time-implications for EHR design. J Eval Clin Pract 20:896-901, 2014

4. Asher AL, McCormick PC, Selden NR, Ghogawala Z, McGirt MJ: The National Neurosurgery Quality and Outcomes Database and NeuroPoint Alliance: rationale, development, and implementation. Neurosurg Focus 34(1):E2, 2013

5. Association of American Medical Colleges: Physician supply and demand through 2025: key findings. AAMC. org. (https://www.aamc.org/download/426260/data/ physiciansupplyanddemandthrough2025keyfindings.pdf) [Accessed August 9, 2016]

6. Babu R, Thomas S, Hazzard MA, Lokhnygina YV, Friedman AH, Gottfried ON, et al: Morbidity, mortality, and health care costs for patients undergoing spine surgery following the ACGME resident duty-hour reform: Clinical article. J Neurosurg Spine 21:502-515, 2014

7. Ban VS, Madden CJ, Bailes JE, Hunt Batjer H, Lonser RR: The science and questions surrounding chronic traumatic encephalopathy. Neurosurg Focus 40(4):E15, 2016

8. Ban VS, Madden CJ, Patel AR, Batjer HH: The Raney brothers and the invention of the Raney clips. J Neurosurg 124:A1199, 2016 (Abstract \#816)

9. Bebawy JF, Gupta DK, Bendok BR, Hemmer LB, Zeeni C, Avram MJ, et al: Adenosine-induced flow arrest to facilitate intracranial aneurysm clip ligation: dose-response data and safety profile. Anesth Analg 110:1406-1411, 2010

10. Bebawy JF, Zeeni C, Sharma S, Kim ES, DeWood MS, Hemmer LB, et al: Adenosine-induced flow arrest to facilitate intracranial aneurysm clip ligation does not worsen neurologic outcome. Anesth Analg 117:1205-1210, 2013

11. Benabid AL: Deep brain stimulation for Parkinson's disease. Curr Opin Neurobiol 13:696-706, 2003

12. Benabid AL, Pollak P, Gao D, Hoffmann D, Limousin P, Gay E, et al: Chronic electrical stimulation of the ventralis intermedius nucleus of the thalamus as a treatment of movement disorders. J Neurosurg 84:203-214, 1996

13. Bendok BR, Gupta DK, Rahme RJ, Eddleman CS, Adel JG, Sherma AK, et al: Adenosine for temporary flow arrest during intracranial aneurysm surgery: a single-center retrospective review. Neurosurgery 69:815-821, 2011

14. Bernat JL: Challenges to ethics and professionalism facing the contemporary neurologist. Neurology 83:1285-1293, 2014

15. Berwick D, Wilensky G, Alexander B, Asch D, Asprey D, Berg A, et al: Graduate Medical Education That Meets the Nation's Health Needs. Washington, DC: Institute of Medicine of the National Academies. (http://www. nationalacademies.org/hmd/Reports/2014/Graduate-MedicalEducation-That-Meets-the-Nations-Health-Needs.aspx) [Accessed August 9, 2016]

16. Bickler SW, Spiegel D: Improving surgical care in low- and middle-income countries: a pivotal role for the World Health Organization. World J Surg 34:386-390, 2010

17. Bilimoria KY, Chung JW, Hedges LV, Dahlke AR, Love R, Cohen ME, et al: National cluster-randomized trial of dutyhour flexibility in surgical training. N Engl J Med 374:713727, 2016

18. Bina RW, Lemole GM Jr, Dumont TM: On resident duty hour restrictions and neurosurgical training: review of the literature. J Neurosurg 124:842-848, 2016

19. Blavatnik Awards for Young Scientists: Edward Chang, 2015 National Award Winner - Faculty. (http:// blavatnikawards.org/honorees/profile/edward-chang/) [Accessed August 9, 2016]

20. Blum AB, Shea S, Czeisler CA, Landrigan CP, Leape L: Im- 
plementing the 2009 Institute of Medicine recommendations on resident physician work hours, supervision, and safety. Nat Sci Sleep 3:47-85, 2011

21. Bouchard KE, Mesgarani N, Johnson K, Chang EF: Functional organization of human sensorimotor cortex for speech articulation. Nature 495:327-332, 2013

22. Bridwell KH, Harner CD, Polly DW Jr, Stern PJ: Symposium. Subspecialty certification: current status of orthopaedic subspecialty certification. J Bone Joint Surg Am 88:20812090, 2006

23. Brotherton SE: Pediatric subspecialty training, certification, and practice: who's doing what. Pediatrics 94:83-89, 1994

24. Campbell EM, Sittig DF, Ash JS, Guappone KP, Dykstra RH: Types of unintended consequences related to computerized provider order entry. J Am Med Inform Assoc 13:547-556, 2006

25. Dall T, West T, Chakrabarti R, Lacobucci W: 2016 Update. The Complexities of Physician Supply and Demand Projections from 2014 to 2025. Final Report. Washington, DC: Association of American Medical Colleges, 2016 (https://www.aamc.org/download/458082/data/2016 complexities_of_supply_and_demand_projections.pdf) [Accessed August 9, 2016]

26. Davey LM: Louise Eisenhardt, M.D.: first editor of the Journal of Neurosurgery (1944-1965). J Neurosurg 80:342-346, 1994

27. Dedhia RC, Yaremchuk KL: The uncertain fate of otolaryngology in sleep medicine. Otolaryngol Head Neck Surg 152:381-382, 2015

28. Dumont TM, Tranmer BI, Horgan MA, Rughani AI: Trends in neurosurgical complication rates at teaching vs nonteaching hospitals following duty-hour restrictions. Neurosurgery 71:1041-1046, 2012

29. Dwyer AP, Herkowitz HN, Benzel EC: Controversies in spine: should there be subspecialty certification in spine surgery? Spine (Phila Pa 1976) 27:1478-1483, 2002

30. Eichenwald K: Medical mystery: making sense of ABIM's financial report. Newsweek. May 21, 2015. (http://www. newsweek.com/2015/06/05/medical-mystery-making-senseabims-financial-report-334772 html) [Accessed August 9, 2016]

31. Eichenwald K: The ugly civil war in American medicine. Newsweek. March 10, 2015. (http://www.newsweek. com/2015/03/27/ugly-civil-war-american-medicine-312662. html) [Accessed August 9, 2016]

32. Ellenbogen RG: Concussion advocacy and legislation: a neurological surgeon's view from the epicenter. Neurosurgery 75 (Suppl 4):S122-S130, 2014

33. Ellenbogen RG, Berger MS, Batjer HH: The National Football League and concussion: leading a culture change in contact sports. World Neurosurg 74:560-565, 2010

34. Fontes RB, Selden NR, Byrne RW: Fostering and assessing professionalism and communication skills in neurosurgical education. J Surg Educ 71:e83-e89, 2014

35. Friedman RC, Bigger JT, Kornfeld DS: The intern and sleep loss. N Engl J Med 285:201-203, 1971

36. Ganju A, Kahol K, Lee P, Simonian N, Quinn SJ, Ferrara JJ, et al: The effect of call on neurosurgery residents' skills: implications for policy regarding resident call periods. J Neurosurg 116:478-482, 2012

37. Goodell R, Batjer HH, Ellenbogen RG: Accelerating progress on the road to safer sports: based on remarks of NFL Commissioner Roger Goodell in the Neurosurgical Society of America (NSA) medal lecture. Neurosurgery 75 (Suppl 4):S119-S121, 2014

38. Govindarajan A, Urbach DR, Kumar M, Li Q, Murray BJ, Juurlink D, et al: Outcomes of daytime procedures performed by attending surgeons after night work. N Engl J Med 373:845-853, 2015
39. Groff MW, Adams DC, Kahn RA, Kumbar UM, Yang BY, Bederson JB: Adenosine-induced transient asystole for management of a basilar artery aneurysm. Case report. J Neurosurg 91:687-690, 1999

40. Hoh BL, Neal DW, Kleinhenz DT, Hoh DJ, Mocco J, Barker FG II: Higher complications and no improvement in mortality in the ACGME resident duty-hour restriction era: an analysis of more than 107,000 neurosurgical trauma patients in the Nationwide Inpatient Sample database. Neurosurgery 70:1369-1382, 2012

41. Kassell NF, Boarini DJ, Olin JJ, Sprowell JA: Cerebral and systemic circulatory effects of arterial hypotension induced by adenosine. J Neurosurg 58:69-76, 1983

42. Kline DG, Mahaley MS Jr: Recognition of special qualifications in neurological surgery. J Neurosurg 64:531-536, 1986

43. Langlois JA, Rutland-Brown W, Wald MM: The epidemiology and impact of traumatic brain injury: a brief overview. $\mathbf{J}$ Head Trauma Rehabil 21:375-378, 2006

44. Lasker Foundation: 2014 Lasker DeBakey Clinical Medical Research Award. Deep brain stimulation for Parkinson's disease. (http://www.laskerfoundation.org/ awards/show/deep-brain-stimulation-for-parkinsons-disease/) [Accessed August 9, 2016]

45. Layliev J, Broer PN, Saadeh PB, Crisera CA, Wu LC, Boyd $\mathrm{JB}$, et al: The certificate of added qualifications in microsurgery: consideration for subspecialty certification in microvascular surgery in the United States. Plast Reconstr Surg 135:313-316, 2015

46. Lee MYH: Carly Fiorina's claim that 307,000 veterans 'died waiting for health care.' Washington Post. September 21, 2015. (https://www.washingtonpost.com/news/fact-checker/ $\mathrm{wp} / 2015 / 09 / 21 /$ carly-fiorinas-claim-that-307000-veteransdied-waiting-for-health-care/) [Accessed August 9, 2016]

47. Ligon BL: The mystery of angiography and the "unawarded" Nobel Prize: Egas Moniz and Hans Christian Jacobaeus. Neurosurgery 43:602-611, 1998

48. Limousin P, Pollak P, Benazzouz A, Hoffmann D, Le Bas JF, Broussolle E, et al: Effect of parkinsonian signs and symptoms of bilateral subthalamic nucleus stimulation. Lancet 345:91-95, 1995

49. Lingenfelser T, Kaschel R, Weber A, Zaiser-Kaschel H, Jakober B, Küper J: Young hospital doctors after night duty: their task-specific cognitive status and emotional condition. Med Educ 28:566-572, 1994

50. Lucey CR, Golub RM: Value, social contracts, and medical education. JAMA 312:2345-2347, 2014

51. Maroon JC, Winkelman R, Bost J, Amos A, Mathyssek C, Miele V: Chronic traumatic encephalopathy in contact sports: a systematic review of all reported pathological cases. PLoS One 10:e 0117338,2015

52. McCormick F, Kadzielski J, Evans BT, Landrigan CP, Herndon J, Rubash $\mathrm{H}$ : Fatigue optimization scheduling in graduate medical education: reducing fatigue and improving patient safety. J Grad Med Educ 5:107-111, 2013

53. McCrory P, Meeuwisse WH, Aubry M, Cantu B, Dvořák J, Echemendia RJ, et al: Consensus statement on concussion in sport: the 4th International Conference on Concussion in Sport held in Zurich, November 2012. J Am Coll Surg 216:e55-e71, 2013

54. Mehta GU, Heiss JD, Park JK, Asthagiri AR, Zaghloul KA, Lonser RR: Neurological surgery at the National Institutes of Health. World Neurosurg 74:49-59, 2010

55. Mesgarani N, Chang EF: Selective cortical representation of attended speaker in multi-talker speech perception. Nature 485:233-236, 2012

56. Mesgarani N, Cheung C, Johnson K, Chang EF: Phonetic feature encoding in human superior temporal gyrus. Science 343:1006-1010, 2014

57. N. Y. Comp. Codes R. \& Regs. Tit. 10, § 405.4(b)(6)(ii) 
58. O'Day DM, Wilkinson CP: Realities regarding subspecialty accreditation and certification in ophthalmology. Retina 30:537-541, 2010

59. Ogden CL, Carroll MD, Kit BK, Flegal KM: Prevalence of childhood and adult obesity in the United States, 2011-2012. JAMA 311:806-814, 2014

60. Osborne R, Parshuram CS: Delinking resident duty hours from patient safety. BMC Med Educ 14 (Suppl 1):S2, 2014

61. Philibert I, Taradejna C: A brief history of duty hours and resident education, in Philibert I, Amis S Jr (eds): The ACGME 2011 Duty Hour Standards: Enhancing Quality of Care, Supervision, and Resident Professional Development. Chicago: Accreditation Council for Graduate Medical Education. (https://www.acgme.org/Portals/0/PDFs/ jgme-11-00-5-11[1].pdf) [Accessed August 9, 2016]

62. Sandhu AT, Dudley RA, Kazi DS: A cost analysis of the American Board of Internal Medicine's Maintenance-ofCertification Program. Ann Intern Med 163:401-408, 2015

63. Selden NR, Anderson VC, McCartney S, Origitano TC, Burchiel KJ, Barbaro NM: Society of Neurological Surgeons boot camp courses: knowledge retention and relevance of hands-on learning after 6 months of postgraduate year 1 training. J Neurosurg 119:796-802, 2013

64. Selden NR, Barbaro N, Origitano TC, Burchiel KJ: Fundamental skills for entering neurosurgery residents: report of a Pacific region "boot camp" pilot course, 2009. Neurosurgery 68:759-764, 2011

65. Selden NR, Origitano TC, Burchiel KJ, Getch CC, Anderson VC, McCartney S, et al: A national fundamentals curriculum for neurosurgery PGY1 residents: the 2010 Society of Neurological Surgeons boot camp courses. Neurosurgery 70:971-981, 2012

66. Selden NR, Origitano TC, Hadjipanayis C, Byrne R: Modelbased simulation for early neurosurgical learners. Neurosurgery 73 (Suppl 1):15-24, 2013

67. Shastry A: More than 300,000 dead vets still on VA's active health care enrollment list. Washington Times. September 2, 2015. (http://www.washingtontimes.com/ news/2015/sep/2/300k-dead-vets-va-health-care-enrollmentlist/?page=all) [Accessed August 9, 2016]

68. Sheehan JP, Kavanagh BD, Asher A, Harbaugh RE: Inception of a national multidisciplinary registry for stereotactic radiosurgery. J Neurosurg 124:155-162, 2016

69. Slack D: VA bosses in 7 states falsified vets' wait times for care. USA Today. April 7, 2016. (http://www.usatoday.com/ story/news/politics/2016/04/07/va-wait-time-manipulationveterans/82726634/) [Accessed August 9, 2016]

70. Sloffer CA, Lanzino G: Historical vignette. Dominique Anel: father of the Hunterian ligation? J Neurosurg 104:626-629, 2006

71. Society of Neurological Surgeons: CAST History. (https:// www.societyns.org/fellowships/HistoryTest.asp) [Accessed August 9, 2016]

72. Sollevi A, Lagerkranser M, Irestedt L, Gordon E, Lindquist $\mathrm{C}$ : Controlled hypotension with adenosine in cerebral aneurysm surgery. Anesthesiology 61:400-405, 1984

73. Spiegel DA, Abdullah F, Price RR, Gosselin RA, Bickler SW: World Health Organization Global Initiative for Emergency and Essential Surgical Care: 2011 and beyond. World J Surg 37:1462-1469, 2013

74. Spritz N: Oversight of physicians' conduct by state licensing agencies. Lessons from New York's Libby Zion case. Ann Intern Med 115:219-222, 1991

75. Stein MB, Kessler RC, Heeringa SG, Jain S, Campbell-Sills L, Colpe LJ, et al: Prospective longitudinal evaluation of the effect of deployment-acquired traumatic brain injury on posttraumatic stress and related disorders: results from the Army
Study to Assess Risk and Resilience in Servicemembers (Army STARRS). Am J Psychiatry 172:1101-1111, 2015

76. Tempesta D, Cipolli C, Desideri G, De Gennaro L, Ferrara $\mathrm{M}$ : Can taking a nap during a night shift counteract the impairment of executive skills in residents? Med Educ 47:1013-1021, 2013

77. VA Office of Inspector General: Veterans Health Administration Interim Report. Review of Patient Wait Times, Scheduling Practices, and Alleged Patient Deaths at the Phoenix Health Care System. Washington, DC: Veterans Health Administration, 2014 (http://www.va.gov/ oig/publications/report-summary.asp?id=3115) [August 9, 2016]

78. VA Office of Inspector General: Veterans Health Administration. Review of Alleged Mismanagement at the Health Eligibility Center. Washington, DC: Veterans Health Administration, 2015 (http://www.va.gov/oig/publications/ report-summary.asp?id=3586) [Accessed August 9, 2016]

79. Vadera S, Griffith SD, Rosenbaum BP, Chan AY, Thompson NR, Kshettry VR, et al: National incidence of medication error in surgical patients before and after Accreditation Council for Graduate Medical Education duty-hour reform. J Surg Educ 72:1209-1216, 2015

80. Walker AE: A History of Neurological Surgery, ed 1. Baltimore: Williams \& Wilkins, 1951

81. Weiner JP, Kfuri T, Chan K, Fowles JB: "e-Iatrogenesis": the most critical unintended consequence of CPOE and other HIT. J Am Med Inform Assoc 14:387-389, 2007

82. Westhead R: Researcher sheds light on exam of former NHL player Todd Ewen's brain. TSN.ca. February 10, 2016. (http:// www.tsn.ca/talent/researcher-sheds-light-on-exam-of-formernhl-player-todd-ewen-s-brain-1.436245) [Accessed August 9, 2016]

83. Wilberger JE, Hoffman HJ, Fabi RA, Reilly GD, Tahmouresie A, Alexander E Jr, et al: Subspecialty certification. Surg Neurol 47:403-411, 1997

84. Williams R: Alim-Louis Benabid: stimulation and serendipity. Lancet Neurol 9:1152, 2010

85. Wright JM, Huang CL, Sharma R, Manjila S, Xu F, Dabb B, et al: Cardiac standstill and circulatory flow arrest in surgical treatment of intracranial aneurysms: a historical review. Neurosurg Focus 36(4):E10, 2014

86. Yaghoubian A, Kaji AH, Ishaque B, Park J, Rosing DK, Lee $\mathrm{S}$, et al: Acute care surgery performed by sleep deprived residents: are outcomes affected? J Surg Res 163:192-196, 2010

\section{Disclosures}

Dr. Batjer reports being co-chair of the NFL Head, Neck and Spine Committee and co-chair of the Texas Institute for Brain Injury and Repair.

\section{Author Contributions}

Conception and design: Batjer. Acquisition of data: both authors. Analysis and interpretation of data: both authors. Drafting the article: Batjer. Critically revising the article: both authors. Reviewed submitted version of manuscript: both authors. Approved the final version of the manuscript on behalf of both authors: Batjer. Administrative/technical/material support: Ban. Supervision: Batjer.

\section{Correspondence}

H. Hunt Batjer, Department of Neurological Surgery, University of Texas Southwestern Medical Center, 5323 Harry Hines Blvd., Dallas, TX 75390-8855. email: hunt.batjer@utsouthwestern.edu. 